\title{
Coupled fixed points and $\alpha$-dense curves
}

\author{
G. GARCÍA
}

\section{ABSTRACT.}

We present a new iterative method, based on the so called $\alpha$-dense curves, to approximate coupled fixed points of nonexpansive mappings. Compactness condition on the mapping or its domain of definition is necessary. As application, we construct a sequence which converges to a solution of certain system of integral equations of Volterra type.

Acknowledgements. The author is grateful to the anonymous referee for extremely careful reading of the first version of the manuscript and for suggesting the ways to improve it further.

\section{REFERENCES}

[1] Agarwal, R., Meehan, M. and O'regan, D., Fixed point theory and applications, Cambridge University, Press 2004

[2] Aghajani A., Allahyari, R. and Mursaleen, M., A generalization of Darbo's theorem with application to the solvability of systems of integral equations, J. Comput. Appl. Math., 260 (2014), 68-77

[3] Aghajani, A. and Sabzali, N., Existence of coupled fixed points via measure of noncompactness and applications, J. Nonlinear Convex Anal., 15 (2014), No. 5, 941-952

[4] Bhaskar, T. G. and Lakshmikantham, V., Fixed point theorems in partially ordered partial metric spaces and applications, Nonlinear Anal., 65 (2006), 1379-1393

[5] Berinde, V., Iterative approximation of fixed points. Second edition, Lecture Notes in Mathematics, 1912, Springer, Berlin, 2007

[6] Berinde, V., Khan, A. R., and Păcurar, M., Coupled solutions for a bivariate weakly nonexpansive operator by iterations, Fixed Point Theory Appl., 2014, 2014:149

[7] Berinde, M. and Păcurar, M., A constructive approach to coupled fixed point theorems in metric spaces, Carpathian J. Math., 31 (2015), No. 3, 277 - 287

[8] Bota, M. F., Petruşel, A., Petruşel, G. and Samet, B., Coupled fixed point theorems for single-valued operators in b-metric spaces, Fixed Point Theory Appl., 2015, 2015:231

[9] Chang, S. S., Cho, Y. J. and Huang, N. J., Coupled fixed point theorems with applications, J. Korean Math. Soc. 33 (1996), No. 3, 575-585

[10] Chen, Y. Z., Existence theorems of coupled fixed points, J. Math. Anal. Appl., 154 (1991), No. 1, 142-150

[11] Cherruault, Y. and Mora, G., Optimisation Globale. Théorie des courbes $\alpha$-denses, Económica, Paris, 2005

[12] Cho, Y. J., Shah, M. H. and Hussain, N., Coupled fixed points of weakly F-contractive mappings in topological spaces, Appl. Math. Lett., 24 (2011), 1185-1190

[13] Dhage, B. C., The Dhage iteration principle for coupled PBVPS of nonlinear second order differential equations, Int. J. Anal. and Appl., 8 (2015), No. 1, 53-62

[14] Goebel, K. and Kirk, W. A., Topics in metric fixed points theory, Cambridge University Press, 2002

[15] Guo, D. and Lakshmikantham, V., Coupled fixed points of nonlinear operators with applications, Nonlinear Anal., 11 (1987), No. 5, 623-632

[16] Kelley, J. L., General Topology, Springer, New York, 1955

[17] Martin, R. H., Nonlinear operators and differential equations in Banach spaces, John Wiley and Sons, 1976

Received: 12.03.2016; In revised form: 01.07.2016; Accepted: 15.07.2016

2010 Mathematics Subject Classification. 47H10,47B07.

Key words and phrases. Coupled fixed point, $\alpha$-dense curves, systems of integral equations of Volterra type. 
[18] Mora, G., Optimization by space-densifying curves as a natural generalization of the Alienor method, Kybernetes, 29 (2000), No. 5-6, 746-754

[19] Mora, G. and Cherruault, Y., Characterization and generation of $\alpha$-dense curves, Comput. Math. Appl., 33 (1997), No. 9, 83-91

[20] Mora, G. and Cherruault, Y., An approximation method for the optimization of continuous functions of $n$ variables by densifying their domains, Kybernetes 28 (1999), No. 2, 164-180

[21] Mora, G. and Mira, J. A., Alpha-dense curves in infinite dimensional spaces, Inter. Journal of Pure and Appl. Math., 5 (2003), No. 4, 437-449

[22] Mora, G. and Redtwitz, D. A., Densifiable metric spaces, Rev. R. Acad. Cienc. Exactas Fís. Nat. Ser. A Math. RACSAM 105 (2011), No. 1, 71-83

[23] Olaoluwa, H., Olaleru, J. O. and Chang, S. S., Coupled fixed point theorems for asymptotically nonexpansive mappings, Fixed Point Theory Appl., 2013, 2013: 68

[24] Sagan, H., Space-filling curves, Springer-Verlag, New York, 1994

[25] Samadia, A. and Ghaemi, M. B., An extension of Darbo fixed point theorem and its applications to coupled fixed point and integral equations, Filomat, 28 (2014), No. 4, 879-886

[26] Shatanawi, W., Samet, B. and Abbas, M., Coupled fixed point theorems for mixed monotone mappings in ordered partial metric spaces, Math. Comput. Modelling, 55 (2012), No. 3-4, 680-687

[27] Sorkun, H. H. and Yalçinbaş, S., Approximate solutions of linear Volterra integral equation systems with variable coefficients, Appl. Math. Model., 34 (2010), 3451-3464

[28] Yaghouti, M. R., Numerical method for solving a system of Volterra integral equations, World Appl. Programming, 2 (2012), No. 1, 18-33

DEPARTMENT OF MATHS.

Universidad Nacional de EdUcación a Distancia (UNED)

CL. CANDAlix S/N, 03202 Elche - Alicante (Spain)

E-mail address: gonzalogarciamacias@gmail.com 